\title{
Pharmacologicals and Phytochemicals Potential of Abutilon indicum: A Comprehensive Review
}

\author{
Md. Reyad-ul-ferdous ${ }^{1,2,3, ~ *}$, Mehedi Rahman ${ }^{2}$, Md. Kawsar Mahamud ${ }^{4}$, Sharmi Sultana Ayshi ${ }^{4}$, \\ Md. Didaruzzaman Sohel ${ }^{3}$
}

${ }^{1}$ Department of Pharmacy, Progati Medical Institute, Dhaka, Bangladesh

${ }^{2}$ Department of Pharmacy, North South University, Dhaka, Bangladesh

${ }^{3}$ Department of Pharmacy, State University of Bangladesh, Dhaka, Bangladesh

${ }^{4}$ Department of Pharmacy, University of development alternative, Dhaka, Bangladesh

Email address:

rockyreyad@yahoo.com (Md. Reyad-ul-ferdous)

\section{To cite this article:}

Md. Reyad-ul-ferdous, Mehedi Rahman, Md. Kawsar Mahamud, Sharmi Sultana Ayshi, Md. Didaruzzaman Sohel. Pharmacologicals and Phytochemicals Potential of Abutilon indicum: A Comprehensive Review. American Journal of BioScience. Special Issue: Pharmacological and Phytochemicals Investigation. Vol. 3, No. 2-1, 2015, pp. 5-11. doi: 10.11648/j.ajbio.s.2015030201.12

\begin{abstract}
Abutilon indicum (Bengali name: Jhampi, Petari, Indian name: Atibala, family: Malvaceae) is extensively grown in Bangladesh, India, Pakistan. The pharmacologicals and biologicals properties and chemicals constituents from the plant $A$. indicum (L.) which is widely used in folk medicine. A. indicum (Malvaceae) is a hairy under-shrub with golden yellow flowers, found in hotter parts of India.This plant is often used as a medicinal plant and is considered invasive on certain tropical islands. In traditional medicine, $A$. indicum is used as a aphrodisiac, demulcent, diuretic, laxative, pulmonary and sedative (leaves). The bark is astringent and diuretic; laxative, expectorant and demulcent (seeds); laxative and tonic, anti-inflammatory and anthelmintic (plant); analgesic (fixed oil); diuretic and for leprosy (roots). The plant is very much used in Siddha medicines. In fact, the bark, root, leaves, flowers and seeds are all used for medicinal purposes by Tamils. The leaves are also used to treat for pile complaints. The flowers are traditionally used to increase semen in men. The phytochemical analysis showed the Presence of Alkaloid, Saponins, Amino acid, Flavonoids, Glycosides and steroids. This plant exhibits several potential pharmacological activities.
\end{abstract}

Keywords: Phytochemicals, Pharmacologicals, Alkaloids, Steroids, Glycosides Phyto Sterols, Analgesic, Abutilon Indicum, Diuretic and Leprosy

\section{Introduction}

Nature is a best friend of our pharmacy field. Natural drugs are effective in action without side effects. Abutilon indicum (Linn.) sweet (Malvaceae) commonly called 'Country Mallow' is a perennial plant up to $3 \mathrm{~m}$ in height. $A$. indicum abundantly found as a weed in the sub-Himalayan tract and in the hotter parts of India. A. indicum is reported to have hypoglycemic, hepatoprotective, antimicrobial, male contraceptive, and antidiarrheal activities [1]. The Leaves of Abutilon indicum are up to $12 \mathrm{~cm}$ long, cordate, ovate, acuminate, tothed rarely subtrilobate, petioles $3.875 \mathrm{~cm}$ long. Stipules $9 \mathrm{~mm}$ long linear acute, deflexed pedicles often 2.5-5 long auxiliary solitary jointed very near the top. Calyx $12.8 \mathrm{~mm}$ long divided to the middle lobes ovate, apisculate. Corolla $2.5 \mathrm{~cm}$ in diameter, opening in the evening. Staminal tube hairy of the base filaments long carpals usually 15-20, longer than the calyx with a distinct small acute point hairy ultimate shining dark brown seed brown black densely minutely scrobiculate. It is fairly common road side weed which grown in hotters part of the India as weed [2]. Plants are an essential and integral component in the world of prescription medicine and have the ability to make various chemical constituents like flavonoids, proteins, alkaloids, and steroids [1], glycosides, phyto sterols, and phenolic compounds, Carbohydrates, amino acids, Saponins, glycosides are isolated from these plants [3], which are in turn used to alleviate many diseases like as body ache, bronchitis, jaundice, toothache, piles, diabetes, fever, leprosy, cystitis, ulcers, gonorrhea, diarrhea[1], cough, urine output, lung disease. They are also used in the treatment of ringing in the ears, deafness, high fever, mumps, pulmonary 
tuberculosis, and cough. The whole herb is used in ayurvedic preparations to treat Hemorrhoids, Diabetes, Menorrhoea. Leaf extracts of $A$. indicum shows hypoglycemic activity in rats [3].

\section{Pharmacological Activities and Medicinal Use of $A$. indicum}

Plants are the major sources of drugs or molecules which demonstrates mild to significant pharmacological activities against tremendous organisms and diseases. Pharmacological activity and phyto-constituents demonstrate in the table-1.

\subsection{Anti Asthmatic Activity of A. indicum}

This study reported the effectiveness of powder of dried aerial parts of Abutilon indicum in decreasing the severity of commonly observed symptoms of bronchial asthma i.e. cough, chest tightness, wheezing and dyspnoea. It was also demonstrate to significantly increase the pulmonary function measured as forced vital capacity (FVC), forced expiratory volume in $1 \mathrm{Sec}$ (FEV1) and peak expiratory flow rate (PEFR) in patients having mild to moderate bronchial asthma. In another study, methanolic extract inhibited experimentally induced rat peritoneal mast cell degranulation and edema formation. The significant reduces in carageenan induced rat paw edema at the dose of 250 and $500 \mathrm{mg} / \mathrm{kg}$, p.o. indicated anti inflammatory activity and this activity was postulated towards the anti-asthmatic effect [4].

\section{Anti-Ulcer Activity of A. indicum}

Present study was carried out to investigate antiulcer activity of methanol extract of $A$. indicum leaves in pylorus ligated and ethanol induced ulceration in the albino rats. Preliminary methanol extract of $A$. indicum was conducted to the acute oral toxicity study according to the OECD guideline no. 425. Based on two dose levels i.e. 250 and 500 $\mathrm{mg} / \mathrm{kg}$ were selected for the further study. Ranitidine at 50 $\mathrm{mg} / \mathrm{kg}$ was used as the standard drug. Methanol extracts of $A$. indicum leaves showed significant $(P<0.05)$ decrease in the gastric volume, free acidity and total acidity. However $\mathrm{pH}$ of the gastric juice was significantly $(P<0.05)$ increased only at higher dose, $500 \mathrm{mg} / \mathrm{kg}$. It showed also significant $(P<0.05)$ decrease in number of ulcers and ulcer score index in pylorus ligation and ethanol induced ulceration models. The results demonstrate significant antiulcer properties in a dose dependent manner. The anti ulcer properties of the extract may be attributed to the presence of phytochemicals like flavonoids (quercetin), alkaloids and tannins present in the plant extract with various biological activities [5].

\subsection{Anti-Arthritic Activity of A. indicum}

The present study deals with anti-arthritic activity in-vitro pharmacological models such as, inhibition of protein denaturation, effect of membrane stabilization, and proteinase inhibitory action. Herbal extract (aq.) with two different concentrations $(100 \mathrm{mcg} / \mathrm{ml}$ and $250 \mathrm{mcg} / \mathrm{ml}$.) was used and results were compared with $(250 \mathrm{mcg} / \mathrm{ml})$ acetyl salicylic acid. The herbal extract showed dose dependent activity which was found to be better than that of acetyl salicylic acid [6].

\subsection{Hepatoprotective Activity of A. indicum}

The aqueous extract of the leaves of $A$. indicum demonstrated significant hepatoprotective activity at 100 and $200 \mathrm{mg} / \mathrm{kg}$ dose levels in $\mathrm{CCl}_{4}$-treated rats. The blood samples were collected and the serum was estimated for SGOT [serum aspartate aminotransferase], SGPT [serum alanine aminotransferase], SAP (serum alkaline phosphatase) and total bilirubin content. $\mathrm{CCl}_{4}$-induced changes were significantly reduced in the $A$. indicum-treated animals [7].

\subsection{Analgesic and Anti-Inflammatory Activity of A. indicum}

In the present study, the analgesic and anti-inflammatory activity of plant extracts of $A$. Indicum was studied. The analgesic activity was found out by eddy's hot plate method by using standard Pentazocin. The anti-inflammatory activity was found out by Carragenan induced paw edema method by using standard Diclofenac sodium. The anti-inflammatory and analgesic activity of Chloroform, Pet.ether, Ethanol \& Aqueous extracts were tested against at a dose level of 400 $\mathrm{mg} / \mathrm{kg}$ body wt. The anti-inflammatory activity showed $* \mathrm{P}<$ 0.001 compared with standard. The analgesic activity showed * $\mathrm{P}<0.001$ compared with standard. In both the activity the methanol and aqueous extract have little more activity than the other extracts [3].

\subsection{Cytotoxic and Antimicrobial Activity of A. indicum}

The investigation was conducted with crude methanolic extract of leaf of $A$. indicum for its cytotoxic and antimicrobial activity. Antimicrobial activity of the extract was evaluated against various Gram-negative, Gram-positive bacteria and fungi using disk diffusion technique. For cytotoxic activity, brine shrimp lethality bioassay was performed to estimate $\mathrm{LC}_{50}$ values. The average zone of inhibition produced by carbon tetrachloride extract was found $7-10 \mathrm{~mm}$ at a concentration of $400 \mu \mathrm{g} / \mathrm{disc}$. The chloroform extract exhibited no antibacterial activity except Sarcina lutea $(8.4 \mathrm{~mm})$. In brine shrimp lethality bioassay, LC obtained from the best-fit line slope were 0.419, 3.01, $5.62^{0}, 1.51$, and $11.20 \mu \mathrm{g} / \mathrm{ml}$ for positive control (vincristine sulfate), n-hexane, carbon tetrachloride, chloroform and aqueous fraction respectively. The cytotoxicity exhibited by chloroform soluble fraction of methanol extract was promising. The carbon tetrachloride extract showed mild to moderate antimicrobial activity [8].

\subsection{Antioxidant Potential and Radical Scavenging Effects of $A$. indicum}

Antioxidant activity of methanolic extract of $A$. indicum leaves was investigated for its free radical scavenging 
activity by determining the nitric oxide and superoxide radical scavenging activity. Maximum scavenging of nitricoxide and superoxide radical found were $28.74 \%$ and 49. $62 \%$ respectively at $250 \mu \mathrm{g} / \mathrm{ml}$ concentration [15] . A. indicum L. (Malvaceae) and A. muticum DC. (Malvaceae) are traditional medicinal herbs used for anthelmintic, hepatoprotective, analgesic and hypoglycemic properties. These effects may be correlated with the presence of antioxidant compounds. Extracts from the aerial parts and roots of both species were prepared and evaluated for their total antioxidant capacity (TAC), total phenolic content, and total flavonoid content. The Trolox equivalent antioxidant capacity (TEAC) of all the extracts of both plants was found, employing ABTS and FRAP assays. TEAC values ranged from 3.019 to $10.5 \mu \mathrm{M}$ for $n$-hexane and butanol fractions of $A$. indicum and from 2.247 to $14.208 \mu \mathrm{M}$ for $n$-hexane and butanol fractions of Abutilon muticum respectively, using the ABTS assay. The FRAP assay showed reducing powers of the fractions in the order of butanol $>$ ethyl acetate $>$ chloroform $>n$-hexane and butanol $>$ chloroform $>$ hexane $>$ ethyl acetate for $A$. indicum and Abutilon muticum, respectively. $\mathrm{EC}_{50}$ and $\mathrm{T}_{\mathrm{EC} 50}$ values for the extracts of both plants were determined using the DPPH free radical assay. The reaction kinetics with this free radical indicated the presence of both slow reacting and fast reacting antioxidant components in the extracts of both plants. The antioxidant/radical scavenging capacity of the extracts was found to be a dose-dependent activity. The results obtained in the present study indicate that both Abutilon species are potential sources of natural antioxidants [9].

\subsection{Antifungal Activity of A. indicum}

A new steroidal compound 20, 23-dimethylcholesta-6, 22dien-3 $\beta$-ol has been isolated from the stem tissues of $A$. indicum. The structure of the compound was elucidated by spectral and chemical studies. The compound was found to be $100 \%$ effective at $5000 \mathrm{ppm}$ in controlling the mycelial growth of Aspergillus terreus var. aureus and Aspergillus parasiticus var. globosus using the poison food technique. For other fungi like A. versicolor, A. flavus, and A. fischeri, it was fungistatic $[10,11]$.

\subsection{Antibacterial Activity of A. indicum}

Chloroform, ethanol and aqueous extracts of the leaves of A. indicum were investigated for antibacterial activity against Staphylococcus aureus, Bacillus subtilis, Klebsiella pneumoniae, Salmonella typhi, Escherichia coli and Pseudomonas aeruginosa. Among the various extracts maximum antibacterial activity was exhibited by ethanol extract $(14,25,14,25,17,18 \mathrm{~mm})$ followed by chloroform extract $(13,17,8,15,15,20 \mathrm{~mm})$ while aqueous extract, showed no activity $[12,11]$.

\subsection{Anti-Diabetic Activity of A. indicum}

Administration of the extract $(0.5$ and $1 \mathrm{~g} / \mathrm{kg}$ body weight) in an oral glucose tolerance test led to a significant reduction in plasma glucose levels in 30 minutes after the administration in moderately diabetic rats, as compared with untreated rats $(\mathrm{P}<\mathrm{b} .05)$, and this was at a faster rate than the use of an glibenclamide, antidiabetic drug. The inhibition of glucose absorption through the small intestine was investigated using an everted intestinal sac. The results demonstrated that the extract at concentrations of 0.156 to 5 $\mathrm{mg} / \mathrm{mL}$ caused a reduction of glucose absorption in a dose response manner. The hight response was noted at a dose of $2.5 \mathrm{mg} / \mathrm{mL}$. The promotion of the extract on insulin secretion was confirmed by incubating $\beta$ cell of pancreatic islets and INS-1E insulinoma cells with the extract at 1 to $1000 \mu \mathrm{g} / \mathrm{mL}$. These results suggest that the aqueous extract from the A indicum plant has antidiabetic properties, which inhibited glucose absorption and stimulated insulin secretion. Phytochemical screening also revealed that the extract contained flavonoids, alkaloids, tannins, saponins and glycosides that could account for the observed pharmacologic effects of the plant extract [13].

\subsection{Larvicidal Activity of A. indicum}

Larvicidal activity of crude ethyl acetate, hexane, acetone, petroleum ether and methanol extracts of five medicinal plants such as A. indicum, Aegle marmelos, Jatropha gossypifolia, Euphorbia thymifolia and Solanum torvum were assayed for their toxicity against the early fourth-instar larvae of Culex quinquefasciatus. The larval mortality was observed after $24 \mathrm{~h}$ exposure. All extracts demonstrated moderate larvicidal effects. However, the maximum larval mortality was found in petroleum ether extract of $A$. indicum. In the present study, bioassay-guided fractionation of $A$. indicum led to the separation and identification of a $\beta$-sitosterol as a potential new mosquito larvicidal compound with $\mathrm{LC}_{50}$ value of $11.49,3.58$ and $26.67 \mathrm{ppm}$ against Aedes aegypti L, Anopheles stephensi Liston and C. quinquefasciatus Say (Diptera: Culicidae), respectively. H NMR, C NMR and mass spectral data confirmed the identification of the active compound. $\beta$-sitosterol has been recognized as the active ingredient of many medicinal plant extracts. All the crude extracts when screened for their larvicidal activities indicated toxicity against the larvae of $C$. quinquefasciatus. This article reports the isolation and identification of the $\beta$-sitosterol as well as bioassay data for the crude extracts. There are no reports of $\beta$-sitosterol in the genus $A$. indicum and their larvicidal activities are being evaluated for the first time. Results of this study demonstrated that the petroleum ether extract of $A$. indicum may be considered as a potent source and $\beta$-sitosterol as a new natural mosquito larvicidal agent [14].

\subsection{Cardioprotective Activity of A. indicum}

The ethanolic extract of the roots obtained from $A$. indicum (Malvaceae) was evaluated for protection against Isoproterenol $(150 \mathrm{mg} / \mathrm{kg}$ body wt, s.c) induced myocardial infarction in male Wistar rats. Isoproterenol induced rats showed significant elevation in the levels of serum marker 
enzymes such as Creatinine Kinase- MB, Lactate dehydrogenase (LDH), Aspartate transaminase (AST) and Alanine transaminase (ALT) with significantly increased lipid peroxides and significant decrease in antioxidant parameters viz., Super oxide dismutase (SOD), Catalase (CAT) and Glutathione peroxidase (GPx) in heart homogenate and also increased serum uric acid level. Oral pretreatment with ethanolic root extract of $A$. indicum (100 $\mathrm{mg} / \mathrm{kg}$ body wt) daily for a period of 28 days, reduced significantly the elevated serum marker enzymes and lipid peroxidation and elevated the levels of SOD, CAT and GPX in the heart homogenate and decreased serum uric acid level. Histopathological observation also revealed a marked protection by the extract in myocardial necrotic damage. Our results show that treatment with ethanolic root extract of $A$. indicum $(100 \mathrm{mg} / \mathrm{kg}$ body wt) was safe and highly effective in preventing cardiovascular dysfunction in rats, possibly due to antioxidant property as revealed by the amelioration of histopathological changes and biochemical markers of cardiac tissue damage. However, ethanolic root extract of $A$. indicum $(500 \mathrm{mg} / \mathrm{kg}$ body $\mathrm{wt}$ ) was found to produce myocardial injury on its own and failed to reverse the Isoproterenol induced myocardial injury[15].

\subsection{Lipid Lowering Activity of A. indicum}

Giri et al. [16] studied the lipid lowering activity of Abutilon indicum (L.) leaf extracts in rats using triton and diet induced hyperlipidemic models. The ethanolic and water extract at $400 \mathrm{mg} / \mathrm{kg}$ dose levels inhibited the elevation in serum cholesterol and triglyceride levels on Triton WR 1339 administration rats. The extracts at the same dose level significantly attenuated the elevated serum total cholesterol and triglycerides with an increase in high-density lipoprotein cholesterol in high-fat diet-induced hyperlipidemic rats. The lipid lowering activity of the EtOH and aqueous leaf extracts of $A$. indicum may be attributed to the phytoconstituents present, such as triterpenoids, flavonoids, tannins, glycosides, and saponins in it, as reported for other plant extracts. Saponin derived from Medicago sativa were reported to reduce blood cholesterol by competing with cholesterol at binding sites or interfering with cholesterol biosynthesis in the liver. Phenolic active principle present in Anethum graveolens were observed to be responsible for lowering TC and LDL-C and elevating HDL-C in hypercholesterolaemic rats [12]. Furthermore, it was supposed to be act by interfering with the biosynthesis of cholesterol and utilization of lipids [4].

\subsection{Anti-Diarrhoeal Activity of A. indicum}

Leaf extracts of Abutilon indicum were evaluated for antidiarrhoeal activity by gastro-intestinal motility, castor oilinduced diarrhoea and prostaglandin E2- induced enteropooling in rats wherein the methanolic and aqueous extracts showed significant antidiarrhoeal activity in castor oil-induced diarrhoea and prostaglandin E2- induced diarrhoea. These extracts were reported to reduce diarrhoea by inhibiting intestinal peristalsis, gastrointestinal motility and PGE2 induced enteropooling [4,17].

\subsection{Wound Healing Activity of A. indicum}

The ethanolic extract of Abutilon indicum was studied for wound healing activity-using incision, excision and dead space wound models in albino rats. This extract at a dose of $400-\mathrm{mg} / \mathrm{kg}$ showed significant increase in wound contraction rate, skin breaking strength, granuloma strength and dry granuloma weight. Moreover, the decrease in epithelisation period [4].

\subsection{Immunomodulatory Activity of A. indicum}

Dashputre et al. [19] studied the immunomodulatory activity of ethanolic and aqueous extract of leaves of $A$. indicum $(200 \mathrm{mg} / \mathrm{kg}$ and $400 \mathrm{mg} / \mathrm{kg}$ ) by heamagglutination antibody (HA) titre, delayed type hypersensitivity (DTH), neutrophil adhesion test and carbon clearance test. Study revealed that extract showed a significant increase in both primary and secondary HA titre. It also showed significantly potentiated DTH reaction and increase in percentage neutophil adhesion test. The results of the study reported that both the extracts were found to have a significant immunostimulatory activity on both the specific and non specific immune mechanisms. This activity was said to be attributed to the presence of flavonoids (quercetin), alkaloids, tannins, saponin glycosides and phenolic compounds [4].

\subsection{Anti-Estrogenic Activity of A. indicum}

Johri et al. [20] studied the anti-estrogenic effect of methanolic extracts of $A$. indicum on uterotropic and uterine peroxidase activities in ovariectomized rats. This extract was found to cause significant suppression of enzyme activity as well as uterotropic response induced by estradiol, whereas in the group, not treated with estradiol, a marginal stimulation in peroxidase activity was observed. These changes in peroxidase activity suggested that $A$. indicum must be a highly potent estrogen antagonist with an extremely low degree of estrogenicity [4].

\subsection{Anti-Convulsant Activity of A. indicum}

Anticonvulsant activity of $A$. indicum leaf extracts was investigated by Golwala et al. [18] using Pentylene tetrazole (PTZ) and Maximum Electro Shock (MES) induced convulsions in wistar rats. In PTZ induced convulsions, 100 $\mathrm{mg} / \mathrm{kg}$ and $400 \mathrm{mg} / \mathrm{kg}$ of ethanolic extract was found to increase the onset of clonic convulsions and decreased onset of tonic seizures and thus exhibited a significant anticonvulsant effect. In MES induces seizures, $100 \mathrm{mg} / \mathrm{kg}$ and $400 \mathrm{mg} / \mathrm{kg}$ of ethanolic as well as aqueous extracts showed significant protective effect by increasing the onset of clonic convulsion time and decreasing extensor time as compared to control group. This anticonvulsant effect was attributed to linoleic acid and/or flavonoid constituents present in the extracts $[4,18]$. 


\subsection{Hypoglycemic Activity of A. indicum}

Seetharam et al. [21] studied the hypoglycemic activity of A. indicum leaf extracts in rats. Blood glucose level was measured by using oxidase-peroxidase method. The petrol and $\mathrm{CHCl} 3$ extract of $A$. indicum leaves did not show a significant hypoglycemic activity. On the contrary, the alcoholic extract after oral administration of $400 \mathrm{mg} / \mathrm{kg}$ exhibited significant reduction in the blood glucose levels. Similarly, the aqueous extract had shown significant reduction in blood glucose level. The significant hypoglycemic activity was attributed to the presence of flavanoids and glycosides since, flavonoids are known to regenerate the damaged pancreatic $\beta$-cells and glycosides stimulate the secretion of insulin in $\beta$-cells of pancreas [4].

Classification of $A$. indicum [2]:

Kingdom: Plantae

Order: Malves

Family: Malvaceae

Genus: Abutilon

Species: Abutilon indicum

Table 1. Presenting various chemical constituents of plant A. indicum.

\begin{tabular}{|c|c|c|}
\hline Chemical Compounds & Parts & References \\
\hline Proteins & Root & 23 \\
\hline Alkaloids & Leaf & 20 \\
\hline Amino acid & Leaves & 19 \\
\hline Carbohydrates & Root & 24 \\
\hline Free amino acids & Root & 24 \\
\hline Saponins & Root, Leaf & 23,24 \\
\hline Glycosides & Root, Leaf, Flower & $23,24,2,4$ \\
\hline p-b-D-Glucosyloxybenzoic acid & Whole plants & 25 \\
\hline p-Hydroxybenzoic & Whole plants & 25 \\
\hline Caffeic acid & Whole plants & 25 \\
\hline Carbohydrates & $\begin{array}{l}\text { Different parts of } \\
\text { plants }\end{array}$ & 23 \\
\hline Essential oil & $\begin{array}{l}\text { Different parts of } \\
\text { plants }\end{array}$ & 23 \\
\hline Flavonoids & Root, Leaf & $23,24,2$ \\
\hline Sesquiterpenes & $\begin{array}{l}\text { Different parts of } \\
\text { plants }\end{array}$ & 23 \\
\hline Fatty acids & $\begin{array}{l}\text { Different parts of } \\
\text { plants }\end{array}$ & 23 \\
\hline Free Acid & Root & 23 \\
\hline Sterols & Root, Leaves & 23,2 \\
\hline Tannin & Root,leaves, stem & 23,24 \\
\hline Resin & Root & 23 \\
\hline Mucilage & Leaves & 2 \\
\hline Organic acid & Leaves & 2 \\
\hline Triterpenoids & Leaves & 2 \\
\hline Lute Olin & Flowers & 2 \\
\hline Apigenin & Flowers & 2 \\
\hline Chrysoenol & Flowers & 2 \\
\hline Glucopyranoside & Flowers & 2 \\
\hline 7-0-beta glucopyranoside & Flowers & 2 \\
\hline $\begin{array}{l}\text { Chrysoenol -7-0-beta - } \\
\text { glucopyranoside }\end{array}$ & Flowers & 2,8 \\
\hline Galactomannose & Seeds & 2 \\
\hline D-galactose & Seeds & 2 \\
\hline D-mannose & Seeds & 2 \\
\hline Luteolin & Flowers & 2,8 \\
\hline $\begin{array}{l}\text { Quercetin 7-0-beta } \\
\text { glucopyranoside }\end{array}$ & Flowers & 2 \\
\hline Quercetin 3-0-alpha-- & Flowers & 2 \\
\hline
\end{tabular}

\begin{tabular}{|c|c|c|}
\hline \multicolumn{3}{|l|}{$\begin{array}{l}\text { rhamnopyranosyl(1-6)-beta } \\
\text { glucopyranoside }\end{array}$} \\
\hline Abutlin & Flowers & 2 \\
\hline $\begin{array}{l}\text { (R)-N-(1-methoxycarbonyl-2- } \\
\text { phenylethyl)-4-hydroxy } \\
\text { benzamide }\end{array}$ & Flowers & 2 \\
\hline Methylstigmasterol & Flowers & 8 \\
\hline Quercetin & Flowers & 8,4 \\
\hline Triacontanoic acid & Flowers & 8 \\
\hline $\begin{array}{l}\text { Apigenin 7-0-beta } \\
\text { rhamnopyranosyl }\end{array}$ & Flowers & 8 \\
\hline Uresenol & Flowers & 8 \\
\hline Glycopyronoside & Flowers & 8 \\
\hline Glucose & Leaves & 4 \\
\hline Fructose & Leaves & 4 \\
\hline Galactose & Leaves & 4 \\
\hline Linoleic & Root & 4 \\
\hline Stearic & Root & 4 \\
\hline Palmitic & Root & 4 \\
\hline Lauric & Root & 4 \\
\hline Myristic & Root & 4 \\
\hline Caprylic, & Root & 4 \\
\hline Capric & Root & 4 \\
\hline Sitosterol, & Root & 4 \\
\hline Abutilin A & Root & 4 \\
\hline $\begin{array}{l}\text { (R)-N-(1'-methoxycarbonyl-2'- } \\
\text { phenylethyl)-4-hydroxybenzamide }\end{array}$ & Root & 4 \\
\hline
\end{tabular}

Table 2. Presenting various pharmacological activities attributed to plant $A$. indicum.

\begin{tabular}{ll}
\hline Activity & References \\
\hline Hepatoprotective & 7 \\
Hypoglycemic & 4 \\
Anti diarrhoeal & 4 \\
Anti-Ulcer & 5 \\
Anti-arthritic & 6,4 \\
Analgesic & 3 \\
Anti-inflammatory & 3 \\
Cytotoxic & 8 \\
Antimicrobial & 8 \\
Antioxidant & 22,9 \\
Radical scavenging & 22,9 \\
Antifungal & 10,11 \\
Antibacterial & 12,11 \\
Anti-diabetic & 13 \\
Larvicidal & 14 \\
Cardioprotective & 15 \\
Wound healing & 4 \\
Lipid lowering & 4 \\
Immunomodulatory & 4 \\
Anti-estrogenic & 4 \\
Anti-convulsant & 4 \\
\hline
\end{tabular}

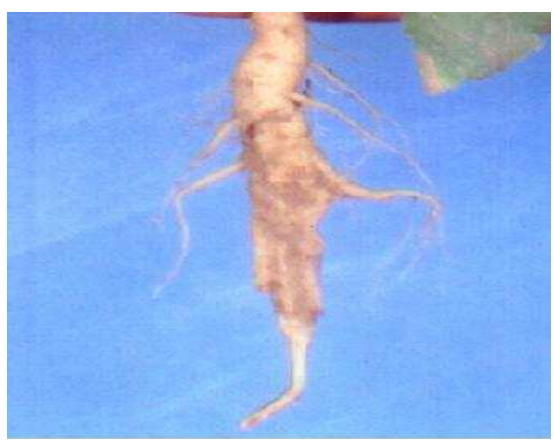

Fig. 1. Root of A. indicum 


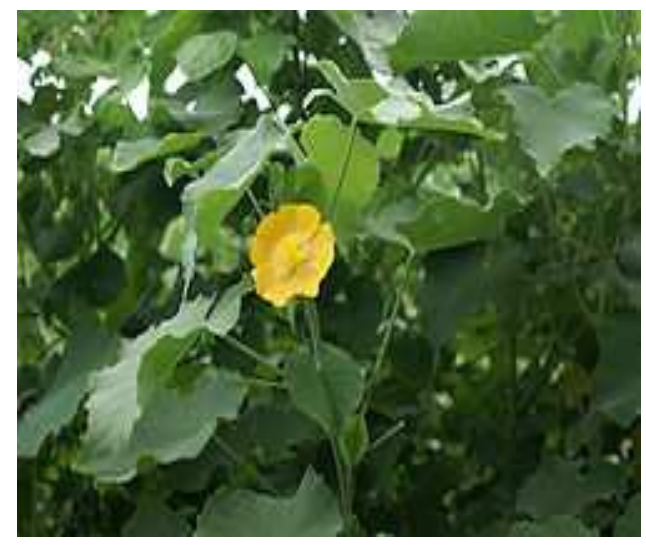

Fig. 2. Flower of $A$. indicum

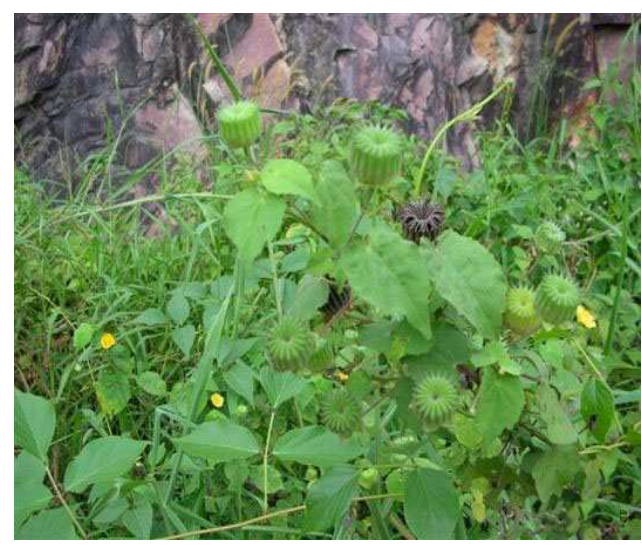

Fig. 3. Whole plant of $A$. indicum

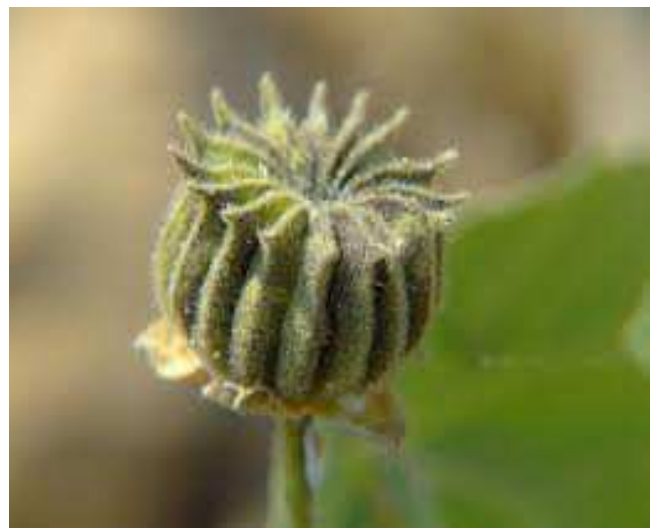

Fig. 4. Fruit of A. indicum



Fig. 5. Leaves of A. indicum

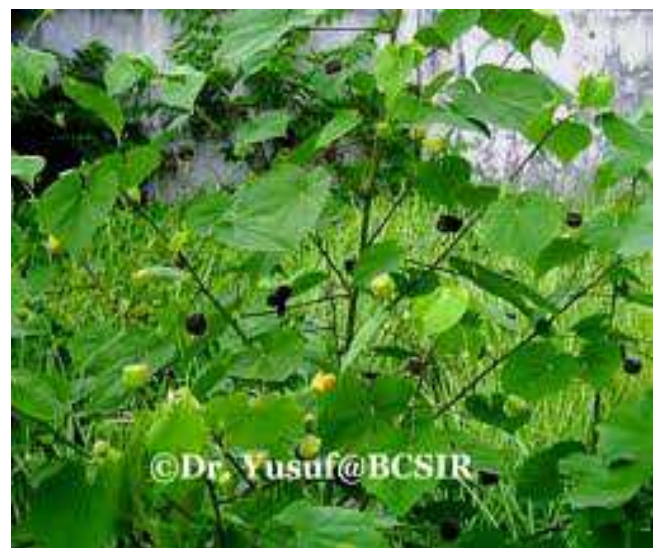

Fig. 6. Stem of A. indicum

\section{References}

[1] Naveen Goyal, Sumitra Singh, Surendra K Sharma, Analgesic effects of various extracts of the root of Abutilon indicum linn Year: 2009 | Volume:1 | Issue:1 | Page:43-46.

[2] Akash Jain, Gaurav Saini, U.B.Moon D.Kumar, Comprehensive Review : Abutilon indicum, Asian Journal of Pharmacy and Life Science,Vol.1(2),March-June,2011, ISSN 2231-4423.

[3] R. Saraswathi, Lokesh Upadhyay, R. Venkatakrishnan, R. Meera, P. Devi, Phytochemical investigation, Analgesic and Anti-inflammatory activity of Abutilon indicum, International Journal of Pharmacy and Pharmaceutical Sciences ISSN0975-1491 Vol 3, Suppl 2, 2011.

[4] Surendra Kr Sharma,Naveen Goyal, Preliminary Phytochemical and Pharmacognostic Profile of Abutilon indicum Linn. Root, Scholars Research Library Der Pharmacia Lettre, 2010, 2(5): 308-315.

[5] N. L. Dashputre, N. S. Naikwade, Evaluation of Anti-Ulcer Activity of Methanolic Extract of Abutilon indicum Linn Leaves in Experimental Rats. International Journal of Pharmaceutical Sciences and Drug Research 2011; 3(2): 97100, ISSN 0975-248X.

[6] Mr. Vallabh Deshpande, Dr. (Mrs.) Varsha M.Jadhav, Dr.V.J.Kadam. Anti-arthritic activity of Abutilon indicum (Linn.) Sweet, Rajesham et al. / Journal of Pharmacy Research 2009, 2(4),644-645, ISSN: 0974-6943.

[7] Dash, G. K.; Samanta, A.; Kanungo, S. K.; Sahu, S. K.; Suresh, P.; Ganapaty, S. Hepatoprotective activity of leaves of Abutilon indicum. Indian Journal of Natural Products $2000 \mathrm{Vol}$. 16 No. 2 pp. 25-27, ISSN0970-129X .

[8] Muhit Md. Abdul, Apu Apurba Sarker, Islam Md. Saiful, Ahmed Muniruddin, Cytotoxic and Antimicrobial Activity of the Crede Extract of Abutilon indicum International Journal of Pharmacognosy and Phytochemical Research 2010;2(1);1-4, ISSN:0975-4873.

[9] Sammia Yasmin, Muhammad Akram Kashmiri, Muhammad Nadeem Asghar ${ }^{2}$, Mushtaq Ahmad, Ayesha Mohy-ud-Din, Antioxidant potential and radical scavenging effects of various extracts from Abutilon indicum and Abutilon muticum. March 2010, Vol. 48, No. 3, Pages 282-289 (doi:10.3109/13880200903110769) . 
[10] Prabhuji S.K, Singh Deepak Kumar, Srivastava Atul Kumar Sinha Rahul . Antifungal activity of a new steroid isolated from Abutilon indicum (L.) Sw. International Journal of Phytomedicines and Related Industries, Year : 2010, Volume : 2, Issue : 3 First page : (215) Last page : (218), Print ISSN : 0975-4261. Online ISSN : 0975-6892. Article DOI: 10.5958/j.0975-4261.2.3.033.

[11] Sammia Yasmin, Muhammad Akram Kashmiri, Iftikhar Ahmad, Ahmad Adnan, Mushtaq Ahmad, Biological Activity of Extracts in Relationship to Structure of Pure Isolates of Abutilon indicum, 2008, Vol. 46, No. 10-11, Pages 673-676 .

[12] M. Poonkothai , Antibacterial Activity of Leaf Extract of Abutilon indicum, Ancient Science of Life Vol : XXVI (1\&2) July, August, September, October, November, December 2006.

[13] Chutwadee Krisanapun, Penchom Peungvicha, Rungravi Temsiririrkkul,Yuvadee Wongkrajang. Aqueous extract of Abutilon indicum Sweet inhibits glucose absorption and stimulates insulin secretion in rodents. Nutrition Research 29 (2009) 579-587.

[14] A. Abdul Rahuman, Geetha Gopalakrishnan, P. Venkatesan and Kannappan Geetha, Isolation and identification of mosquito larvicidal compound from Abutilon indicum (Linn.) Sweet . Parasitology Research, Volume 102, Number 5 (2008), 981-988, DOI: 10.1007/s00436-007-0864-5.

[15] Amaranth KR, Inamdar MN, Cardioprotective activity of ethanolic root extract of Abutilon indicum in isoproterenol induced myocardial infarction in male wistar rats, S98 Indian J Pharmacol | October 2008 | Vol 40 | Supplement 2.

[16] Giri RK, Kanungo SK, Patro VJ, Das S, Sahoo DC. J Pharmacy Res 2009; 2(11): 1725-7.
[17] Chandrashekhar VM, Nagappa AN, Channesh TS, Habbu PV, Rao KP. J Natural Remedies 2004; 1(4): 12-6.

[18] Golwala DK, Patel LD, Vaidya SK, Bothara SB, Mani M, Patel P. Int. J Pharmacy Pharma Sci 2010; 2(1): 66-71.

[19] Dashputre NL, Naikwade NS. Int J Pharma Sci Res 2010; 1(3): 178- 84.

[20] Johri RK, Pahwa GS, Sharma SC, Zutshi U. Contraception 1991; 44(5): 549-57.

[21] Seetharam YM, Chalageri G, Ramachandra Setty S, Bheemachar. Fitoterapia 2002; 73: 156-9.

[22] Guno Sindhu Chakraborthy, Antioxident Activity of Abutilon indicum Leaves. International Journal of PharmTech Research CODEN (USA): IJPRIF ISSN : 0974-4304 Vol.1, No.4, pp 1314-1316, Oct-Dec 2009.

[23] Surendra $\mathrm{Kr}$ Sharma,Naveen Goyal, Preliminary Phytochemical and Pharmacognostic Profile of Abutilon indicum Linn. Root, Scholars Research Library Der Pharmacia Lettre, 2010, 2(5): 308-315.

[24] Suresh,S.N,Sagadevan.P, S.Rathish Kumar, V.Rajeshwari. IJPRD, 2011; Vol 4(02): April-2012 (132 - 135) ... Available online on www.ijprd.com ... Phytochemical Analysis And Antimicrobial Potential of ... Abutilon indicum (Malvaceae).

[25] D. P. Pandey ,M. A. Rather ,D.P. Nautiyal and R. K. Bacheti ,Phytochemical analysis of Abutilon indicum International Journal of ChemTech Research CODEN( USA): IJCRGG ISSN : 0974-4290 Vol. 3, No.2, pp 642-645, AprilJune 2011. 